
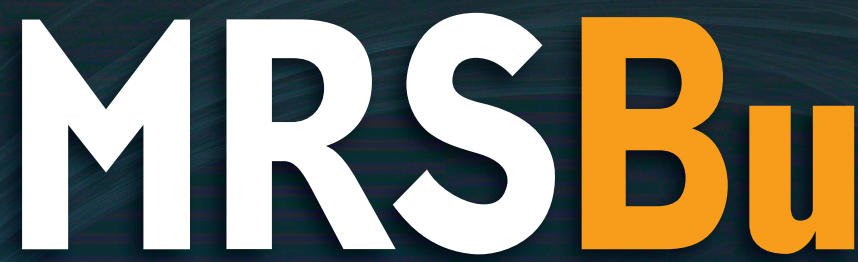

$\mathrm{M}|\mathrm{R}| \mathrm{S}$
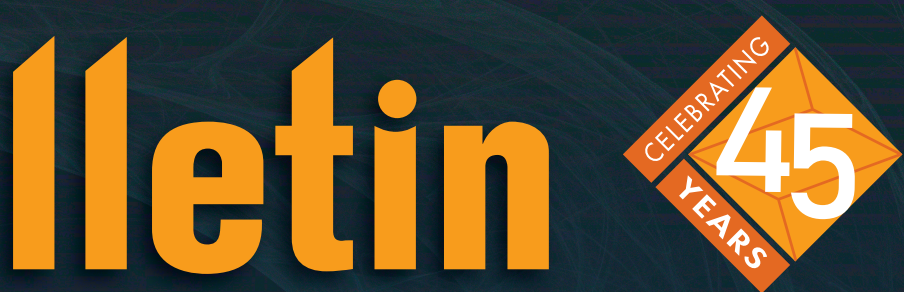

May 2020 Vol. 45 No. 5

mrs.org/bulletin

\title{
Emergent quantum materials
}

\section{ALSO IN THIS ISSUE}

A golden time for nanotechnology

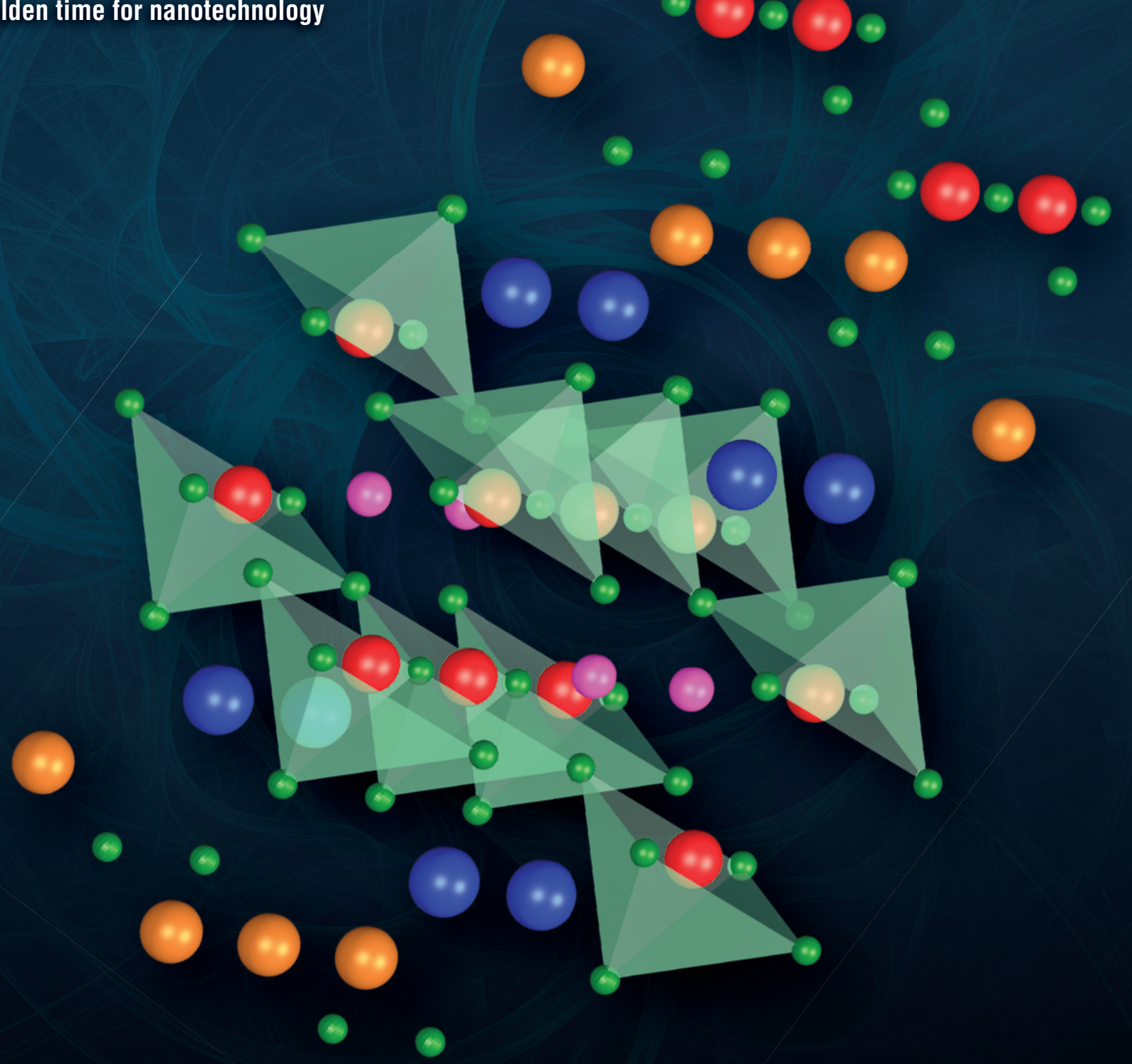




\section{PARTICLE ACCELERATOR SYSTEMS}

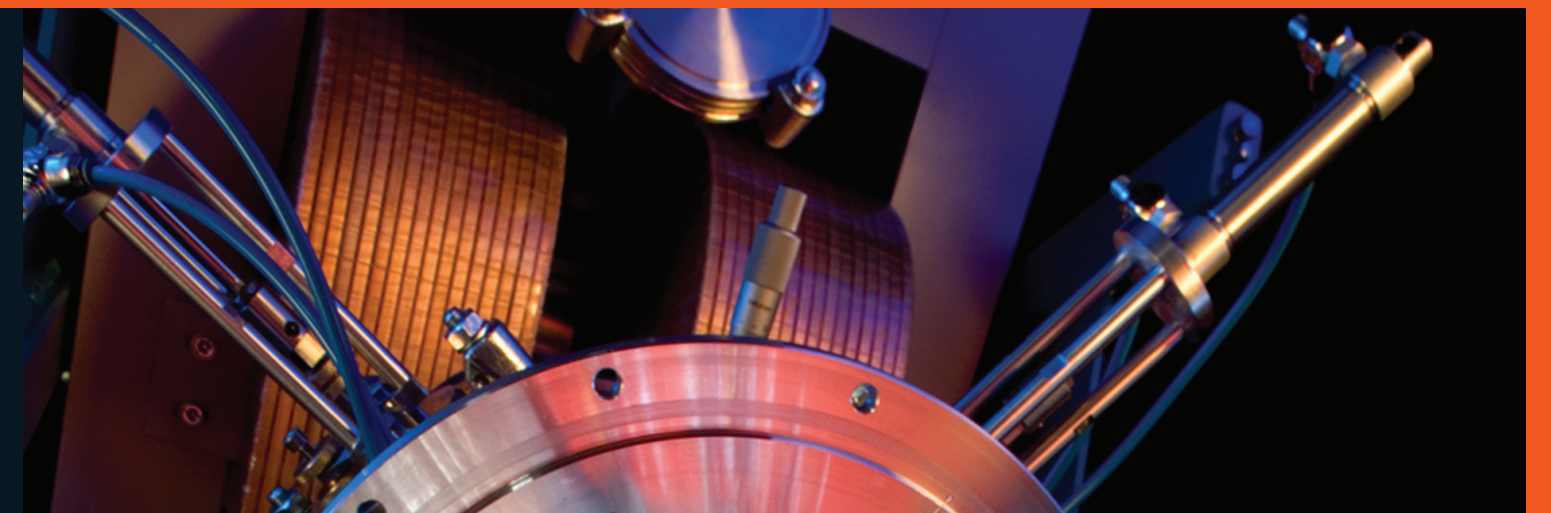

口 Ion Accelerator Systems

- Ion Implanters

- Systems for lon Beam Analysis

- Accelerator Mass Spectrometers

- Systems for $\boldsymbol{\mu}$-beam Applications

- Neutron Generator Systems

Electron Accelerator Systems

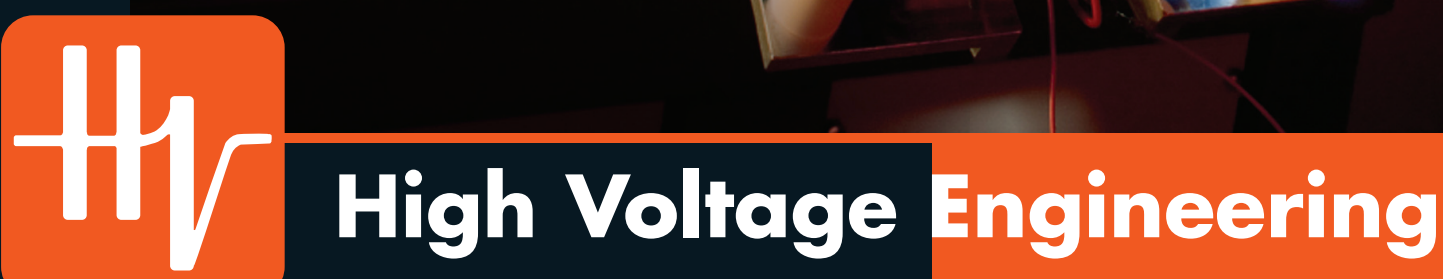

High Voltage Engineering Europa B.V.

P.O. Box 99, 3800 AB Amersfoort, The Netherlands Tel: 31334619741 • info@highvolteng.com 

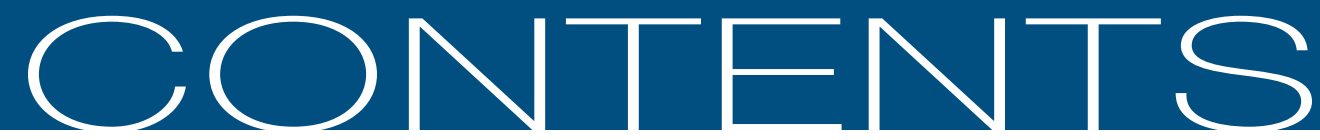

\section{EMERGENT QUANTUM MATERIALS}

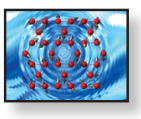

340 Emergent quantum materials

Chun Ning Lau, Fengnian Xia, and Linyou Cao,

Guest Editors

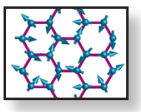

348 Thermal transport for probing quantum materials

Mingda Li and Gang Chen

357 Magnetism, spin dynamics, and quantum transport in two-dimensional systems W. Savero Torres, J.F. Sierra, L.A. Benítez, F. Bonell, J.H. García, S. Roche, and S.0. Valenzuela

366 Emergent high-temperature superconductivity at interfaces

Can-Li Song, Xu-Cun Ma, and Qi-Kun Xue

373 Topological quantum materials

Kang L. Wang, Yingying Wu, Christopher Eckberg,

Gen Yin, and Quanjun Pan

380 Condensation of indirect excitons L.V. Butov

\section{TECHNICAL FEATURE}

387 A golden time for nanotechnology MRS Medal recipient ${ }^{\star}$ at the 2019 MRS Fall Meeting in Boston Huei-Huei Chang, Matthew T. Gole, and Catherine J. Murphy*

\section{MRSBulletin}

Emergent quantum materials

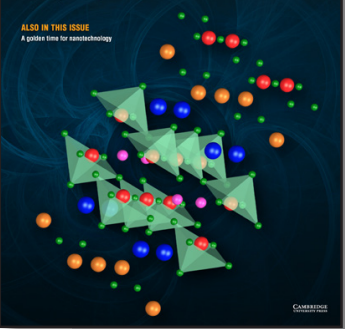

semsen quantum materials at the intersection of materials science and condensedmatter physics. The cover provides a schematic view of monolayer $\mathrm{CuO}_{2}$ films on a Bi-2212 substrate. See the technical theme that begins on p. $\mathbf{3 4 0}$

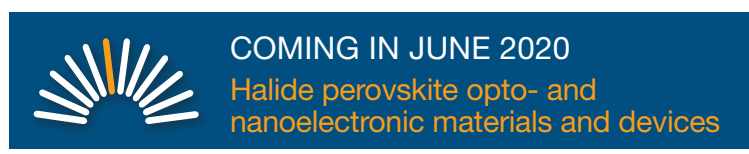




\section{DEPARTMENTS}

\section{OPINION}

325 Letter from the President Navigating unprecedented times Matt Copel

327 Material Matters How can materials science contribute to fighting against the new coronavirus? Hortense Le Ferrand

\section{NEWS \& ANALYSIS}

331 Feature Article

- Shared instrumentation facilities: Benefiting researchers and universities, and sustaining research excellence T. Amanda Strom, Greg Haugstad, Jonathan Shu, and Ram Seshadri

336 Materials News

- Carbon scrolls stabilize silicon nanoparticles in lithium-ion batteries Tianyu Liu

- Tests elucidate high fatigue lifetime of graphene Prachi Patel

338 Science Policy

- UK materials researchers turn to social science in pursuit of sustainable technologies Michael Kenward

- EC awards emergency funds for COVID-19 research

\section{SOCIETY NEWS}

321 MRS Journal Highlights

394 MRS University Chapter Special Project Awards

\section{FEATURES}

399 Announcements

MRS Movers \& Shakers

\section{CAREER CENTRAL}

\section{Career Feature}

US Immigration paths for scientific researchers

Marco Pignone

398 Classified

\section{ADVERTISERS IN THIS ISSUE}

American Elements High Voltage Engineering MCARE 2020 and EHS 2020 Meeting (ACerS) ..

\section{Page No.}

Outside back cover Inside front cover .372

\section{mrs.org/bulletin}

mrs.org/energy-quarterly

mrs.org/mymrs

journals.cambridge.org

mrs.org/bulletin-podcast

@mrsbulletin 


\section{$\mathrm{M}|\mathrm{R}| \mathrm{S}$}

MATERIALS RESEARCH SOCIETY ${ }^{\oplus}$

Advancing materials. Improving the quality of life.
EDITORIAL OFFICE 506 Keystone Drive, Warrendale, PA 15086-7573 USA

Bulletin@mrs.org tel 724.779.2747 fax 724.779.8313 mrs.org

\section{About the Materials Research Society}

The Materials Research Society (MRS), a not-for-profit scientific association founded in 1973 and headquartered in Warrendale, Pennsylvania, USA, promotes interdisciplinary materials research. Today, MRS is a growing, vibrant, member-driven organization of over 16,000 materials researchers spanning over 80 countries, from academia, industry, and government, and a recognized leader in the advancement of interdisciplinary materials research.

The Society's interdisciplinary approach differs from that of single-discipline professional societies because it promotes information exchange across many scientific and technical fields touching materials development. MRS conducts three major international annual meetings and also sponsors numerous single-topic scientific meetings. The Society recognizes professional and technical excellence and fosters technical interaction through University Chapters. In the international arena, MRS implements bilateral projects with partner organizations to benefit the worldwide materials community. The Materials Research Society Foundation helps the Society advance its mission by supporting various projects and initiatives.

2020 MRS BOARD OF DIRECTORS

President Matt Copel, IBM T.J. Watson Research Center, USA

Immediate Past President Michael R. Fitzsimmons, Oak Ridge National

Laboratory and The University of Tennessee, USA

Vice President (President-Elect) Cherie R. Kagan, University of Pennsylvania, USA

Secretary Dawnielle Farrar-Gaines, Johns Hopkins University, USA

Treasurer Shenda Baker, Synedgen Inc., USA

Executive Director Todd M. Osman, Materials Research Society, USA

Griselda Bonilla, IBM T.J. Watson Research Center, USA

Leonard J. Brillson, The Ohio State University, USA

Kristen H. Brosnan, GE Global Research, USA

Kristen H. Brosnan, GE Global Research, USA
Coray M. Colina, University of Florida, USA

Catherine Dubourdieu, Helmholtz-Zentrum Berlin/Freie Universität Berlin, Germany Sarah Heilshorn, Stanford University, USA

Frances A. Houle, Lawrence Berkeley National Laboratory, USA

Mônica Jung de Andrade, The University of Texas at Dallas, USA

Sergei V. Kalinin, Oak Ridge National Laboratory, USA

Kisuk Kang, Seoul National University, Republic of Korea

Paul C. McIntyre, Stanford University, USA

Linda S. Schadler, The University of Vermont, USA

Christopher A. Schuh, Massachusetts Institute of Technology, USA

Rachel A. Segalman, University of California, Santa Barbara, USA

Ting Xu, University of California, Berkeley, USA

Yusheng Zhao, Southern University of Science and Technology, China

Ehrenfried Zschech, Fraunhofer Institute for Ceramic Technologies and Systems, Germany

\section{MRS OPERATING COMMITTEE CHAIRS}

Academic Affairs Sanjay Mathur, University of Cologne, Germany

Awards (Co-chairs) Suveen N. Mathaudhu, University of California, Riverside, USA

Judith L. Driscoll, University of Cambridge, UK

Government Affairs David P. Norton, University of Florida, USA

Meetings Lincoln J. Lauhon, Northwestern University, USA

Public Outreach Elizabeth Kupp, The Pennsylvania State University, USA

Publications Shefford P. Baker, Cornell University, USA

\section{MRS HEADQUARTERS}

Todd M. Osman, Executive Director

J. Ardie Dillen, Director of Finance and Administration

Damon Dozier, Director of Government Affairs

Michele L. Feder, Associate Director of Engagement

Patricia Hastings, Director of Meetings Activities

Eileen M. Kiley, Director of Communications
Editor

Gopal R. Rao, rao@mrs.org

Impact Editor

Markus J. Buehler

Managing Editor

Lori A. Wilson, Iwilson@mrs.org

News Editor

Judy Meiksin, meiksin@mrs.org

Technical Editor

Lisa C. Oldham, oldham@mrs.org

Editorial Assistants

Suzanne Hite, hite@mrs.org,

Mary Wilmoth

Associate Technical Editor

Carol Tseng

Director of Communications

Eileen M. Kiley
Guest Editors

Chun Ning Lau, Fengnian Xia,

and Linyou Cao

Special Consultants

Ken Haenen and Enrico Traversa

Production/Design

Stephanie Gabborin, Heather Shick,

Felicia Turano, and TNQ

Production Editor

Rachel Altizio

Advertising/Sponsorship

Mary E. Kaufold, kaufold@mrs.org

Donna L. Watterson, watterson@mrs.org

Member Subscriptions

Michelle Judt, judt@mrs.org

Non-Member Subscriptions

subscriptions_newyork@cambridge.org

\section{EDITORIAL BOARD}

Amit Misra (Chair), University of Michigan, USA

Ilke Arslan, Argonne National Laboratory, USA

N. (Balu) Balasubramanian, Bangalore, India (retired)

Christopher J. Bettinger, Carnegie Mellon University, USA

Tommie Kelley, 3M, USA

Igor Lubomirsky, Weizmann Institute, Israel

Fiona C. Meldrum, University of Leeds, UK

Steven C. Moss, The Aerospace Corporation, USA (retired)

Linda J. Olafsen, Baylor University, USA

Boaz Pokroy, Technion-Israel Institute of Technology, Israel

Zhiwei Shan, Xi'an Jiaotong University and Hysitron, China

Subhash L. Shinde, University of Notre Dame, USA

Eric Werwa, Washington, DC, USA

M. Stanley Whittingham, Binghamton University, The State University of New York, USA

IMPACT EDITORIAL BOARD

Katia Bertoldi, Harvard University, USA

Huiling Duan, Peking University, China

Peter Fratzl, Max Planck Institute of Colloids and Interfaces, Germany

Pupa Gilbert, University of Wisconsin-Madison/Berkeley National Laboratory, USA

Ali Khademhosseini, University of California, Los Angeles, USA

John A. Rogers, Northwestern University, USA

Francesco Stellacci, École Polytechnique Fédérale de Lausanne, Switzerland

Kathryn E. Uhrich, University of California, Riverside, USA

ADVISORY BOARD

V.S. Arunachalam, Center for Study of Science, Technology and Policy, India

Paul Drzaic, Apple, Inc., USA

Yury Gogotsi, Drexel University, USA

Robert S. Langer, Massachusetts Institute of Technology, USA

Ke Lu, Chinese Academy of Sciences, China

Rodney S. Ruoff, Institute for Basic Science, Center for Multidimensional Carbon Materials and UNIST, South Korea

Edwin L. (Ned) Thomas, Rice University, USA

Peidong Yang, University of California, Berkeley, USA

\section{VOLUME ORGANIZERS}

2020 Hongyou Fan, Sandia National Laboratories, USA Oleg Gang, Columbia University and Brookhaven National Laboratory, USA Seokwoo Jeon, Korea Advanced Institute of Science and Technology, Republic of Korea Tae-Woo Lee, Seoul National University, Republic of Korea

2021 Babu Chalamala, Sandia National Laboratories, USA Paul Evans, University of Wisconsin-Madison, USA Takao Someya, The University of Tokyo, Japan Haiyan Wang, Purdue University, USA

MRS Bulletin (ISSN: 0883-7694, print; ISSN 1938-1425, online) is published monthly by the Materials Research Society, 506 Keystone Drive, Warrendale, PA 15086-7573. ๑ 2020 Materials Research Society. Permission required to reproduce content. Periodical postage paid at New York, NY, and at additional mailing offices. POSTMASTER: Send address changes to MRS Bulletin in care of the Journals Department, Cambridge University Press, 100 Brook Hill Drive, West Nyack, NY 10994-2113, USA. Printed in the U.S.A.

Membership in MRS is $\$ 135$ annually for regular members, $\$ 35$ for students, and includes an electronic subscription to MRS Bulletin. Print subscriptions are available to MRS members for an additional $\$ 25$. Individual member subscriptions are for personal use only. Nonmember subscription rates are \$618 (USD) for one calendar year (12 issues). Requests from subscribers for missing journal issues will be honored without charge only if received within six months of the issue's actual date of publication.

MRS Bulletin is included in Current Contents ${ }^{\circledast} /$ Engineering, Computing, and Technology; Current Contents ${ }^{\circledast} /$ Physical, Chemical, and Earth Sciences, the SciSearch ${ }^{\circledast}$ online database, Research Alert ${ }^{\oplus}$, Science Citation Index ${ }^{\oplus}$, Materials Science Citation Index ${ }^{\top M}$, and Scopus.

Authors of each technical article appearing in MRS Bulletinare solely responsible for all content in their article(s) including accuracy of the facts, statements, and citing resources. Facts and opinions are solely the personal statements of the respective authors and do not necessarily represent the views of the editors, the Materials Research Society, or Cambridge University Press. 